\title{
Effect of Nb doping on chemical stability of BSCF-based solid solutions
}

Fang Wang ${ }^{1}$, Takashi Nakamura ${ }^{1}$, Keiji Yashiro $^{2}$, Junichiro Mizusaki ${ }^{1}$, Koji Amezawa ${ }^{1}$

${ }^{1}$ Institute of Multidisciplinary Research for Advanced Materials, Tohoku University

2-1-1 Katahira, Aoba-ku, Sendai 980-8577, Japan

${ }^{2}$ Graduate School of Environmental Studies, Tohoku University

6-6-01 Aoba, Aramaki, Aoba-ku, Sendai 980-8579, Japan

email: f-wang@mail.tagen.tohoku.ac.jp

\section{Abstract}

Effects of $\mathrm{Nb}$ doping on the chemical stability of $\mathrm{Ba}_{0.5} \mathrm{Sr}_{0.5} \mathrm{Co}_{0.8} \mathrm{Fe}_{0.2} \mathrm{O}_{3-\delta}$ based solid solutions under high oxygen partial pressure $\left(p\left(\mathrm{O}_{2}\right)\right)$ and $\mathrm{CO}_{2}$-containing atmospheres were studied. $\quad \mathrm{BSCF} \quad$ and $\quad \mathrm{Ba}_{0.5} \mathrm{Sr}_{0.5} \mathrm{Co}_{0.9} \mathrm{Nb}_{0.1} \mathrm{O}_{3-\delta} \quad$ (BSCN) and $\mathrm{Ba}_{0.5} \mathrm{Sr}_{0.5} \mathrm{Co}_{0.8} \mathrm{Fe}_{0.1} \mathrm{Nb}_{0.1} \mathrm{O}_{3-\delta}$ (BSCFN) were prepared and investigated by using TG-DTA analysis under $p\left(\mathrm{O}_{2}\right)=1$ and $10^{-3}$ bar with or without of $\mathrm{CO}_{2}$. The results showed the $\mathrm{Nb}$ substitution effectively improved the chemical stability under high oxidation condition and also improves the $\mathrm{CO}_{2}$-tolerance of BSCF-based materials. 
Keywords: BSCF, chemical stability, $\mathrm{Nb}$-doping, $\mathrm{CO}_{2}$ tolerance

\section{Introduction}

Cubic perovskite $\mathrm{Ba}_{0.5} \mathrm{Sr}_{0.5} \mathrm{Co}_{0.8} \mathrm{Fe}_{0.2} \mathrm{O}_{3-\delta}$ (BSCF) is expected as one of the most high-performance cathode materials for IT-SOFCs or oxygen permeable membranes [1]. The high oxygen vacancy concentration and the relatively low activation barrier for the vacancy diffusion bring high ionic conductivity and, consequently, excellent oxygen reduction properties [2-3]. However recent studies suggested the chemical instability of BSCF below the critical temperature of $1123 \mathrm{~K}$ in air [4-9]. Another material instability problem with $\mathrm{BSCF}$ is its high reactivity with $\mathrm{CO}_{2}$ resulting in the formation of $(\mathrm{Ba}, \mathrm{Sr}) \mathrm{CO}_{3}[10-11]$. These instability issues lead to the severe performance degradation as an SOFC cathode or an oxygen permeable membrane [4, 12-13]. Therefore, it is necessary to make a clear assessment on BSCF regarding the chemical stability under high $p\left(\mathrm{O}_{2}\right)$ and $\mathrm{CO}_{2}$-containing atmosphere at operating temperature of IT-SOFCs or oxygen permeable membranes. However, there are only a few estimations on the stability of BSCF in the limited temperature range in air. The chemical stability of BSCF in a wide ranges of $p\left(\mathrm{O}_{2}\right)$ and temperature has not been understood so far.

In our previous work [14], the chemical stability of BSCF was investigated as a

function of $p\left(\mathrm{O}_{2}\right)$ (1 to $10^{-22}$ bar) and temperature (300 to $1373 \mathrm{~K}$ ) by HT-XRD, 
HT-gravimetry and coulometric titration. The decomposition of the cubic perovskite phase of BSCF was confirmed in connection with the oxidation/reduction of Co ions due to the oxygen nonstoichiometry $(\delta)$ change. We found the cubic perovskite phase of BSCF decomposed when cobalt ions were oxidized to higher oxidation state than trivalence in high $p\left(\mathrm{O}_{2}\right)$ or were reduced to lower oxidation state than divalence in low $p\left(\mathrm{O}_{2}\right)$ condition. These results suggested the cubic perovskite phase of BSCF can be stabilized by controlling the oxidation state of Co. Nagai et al. demonstrated that $\mathrm{Nb}$ was the most effective dopant for stabilization of the cubic structure in $\mathrm{SrCo}_{0.9} \mathrm{M}_{0.1} \mathrm{O}_{3-\delta},(\mathrm{M}=\mathrm{Ni}, \mathrm{Cu}, \mathrm{Zn}, \mathrm{Cr}, \mathrm{Fe}, \mathrm{Al}, \mathrm{Ga}, \mathrm{In}, \mathrm{Ce}, \mathrm{Ti}, \mathrm{Zr}, \mathrm{Sn}, \mathrm{V}$ and $\mathrm{Nb})$ [15-16]. They suggested that the sequence of the stabilization effect in high $p\left(\mathrm{O}_{2}\right)$ was $\mathrm{Cu}^{2+}<$ $\mathrm{Cr}^{3+}, \mathrm{Al}^{3+}, \mathrm{Ga}^{3+}<\mathrm{La}^{3+}$ (substituting A site $)<\mathrm{Fe}^{3.108+}<\mathrm{Ti}^{4+}<\mathrm{Nb}^{5+}$. S.M. Fang et al. [17] found the phase instability of BSCF in air condition is suppressed at the substitution of $5 \mathrm{~mol} \%$ of $\mathrm{Nb}$ for the $(\mathrm{Co}, \mathrm{Fe})$-site. These results give us a hypothesis that the stability of the perovskite structure is enhanced by substituting the B-site cations by higher valence cations. These works indirectly support our speculation [14] that lowering the Co mean valence improves the stability of Co-containing perovskite oxides in high $p\left(\mathrm{O}_{2}\right)$ condition. However, the information about the doping effect of higher valence cation $\mathrm{Nb}$ on the chemical stability of BSCF-based materials under high $p\left(\mathrm{O}_{2}\right)$ and 
$\mathrm{CO}_{2}$-containing atmospheres is insufficient.

Therefore, in this work, we substituted higher valence cation, $\mathrm{Nb}^{5+}$, for B-site of BSCF-based solid solutions to improve the chemical stability. The effect of the $\mathrm{Nb}$ substitution on the chemical stability under high $p\left(\mathrm{O}_{2}\right)$ and $\mathrm{CO}_{2}$-containing atmospheres was investigated through thermal analysis by using TG-DTA measurements under $p\left(\mathrm{O}_{2}\right)$ $=1$ and $10^{-3}$ bar with or without 5 vol $\% \mathrm{CO}_{2}$.

\section{Experimental}

\subsection{Synthesis materials}

$\mathrm{Ba}_{0.5} \mathrm{Sr}_{0.5} \mathrm{Co}_{0.8} \mathrm{Fe}_{0.2} \mathrm{O}_{3-\delta}$ (BSCF) was synthesized by Pechini method. Nitrate solutions of $\mathrm{Ba}^{2+}, \mathrm{Sr}^{2+}, \mathrm{Co}^{2+}$ and $\mathrm{Fe}^{3+}$ were prepared by dissolving $\mathrm{BaCO}_{3}, \mathrm{Co}_{3} \mathrm{O}_{4}$, $\mathrm{SrCO}_{3}$ and $\mathrm{Fe}\left(\mathrm{NO}_{3}\right)_{3} \cdot 9 \mathrm{H}_{2} \mathrm{O}$ (all reagents with A.R. purity) in nitric acid or deionized water. The concentrations of the $\mathrm{Ba}, \mathrm{Co}$ and $\mathrm{Sr}$ ions were determined by the chelate titration using EDTA. The concentration of the Fe ions was measured by the inductively coupled plasma atomic emission spectroscopy (Optima 3300, Perkin Elmer, Yokohama, Japan). After mixing the solutions in the appropriate stoichiometric ratios, excess amounts of ethylene glycol and citric acid were added to the mixed solution. The solution was heated to $523 \mathrm{~K}$ and dried, followed by calcining at $1273 \mathrm{~K}$ for $10 \mathrm{~h}$ and 
sintering at $1373 \mathrm{~K}$ for $10 \mathrm{~h} . \quad \mathrm{Ba}_{0.5} \mathrm{Sr}_{0.5} \mathrm{Co}_{0.9} \mathrm{Nb}_{0.1} \mathrm{O}_{3-\delta} \quad(\mathrm{BSCN}) \quad$ and $\mathrm{Ba}_{0.5} \mathrm{Sr}_{0.5} \mathrm{Co}_{0.8} \mathrm{Fe}_{0.1} \mathrm{Nb}_{0.1} \mathrm{O}_{3-\delta}$ (BSCFN) were synthesized by solid state reactions. $\mathrm{BaCO}_{3}$, $\mathrm{Co}_{3} \mathrm{O}_{4}, \mathrm{Fe}_{2} \mathrm{O}_{3}, \mathrm{Nb}_{2} \mathrm{O}_{5}$ (all reagents with A.R. purity) were weighted according to their stoichiometry and mixed. The mixtures were calcined at $1273 \mathrm{~K}$ for $10 \mathrm{~h}$. The primary powders were crashed finely in an agate mortar, and sintered at $1373 \mathrm{~K}$ for $10 \mathrm{~h}$. Obtained powder of BSCN and BSCFN were confirmed to be single phase perovskites by X-ray powder diffraction (XRD) (D2 Phase: $\mathrm{Cu} \mathrm{K} \alpha$ radiation, Bruker AXS, Germany) at room temperature in air.

\subsection{Thermoanalysis}

Differential thermal analysis (DTA) and thermogravimetric analysis (TGA) were performed with BSCF, BSCN and BSCFN samples by the Bruker2000s thermal analyzer $300-1273 \mathrm{~K}$ at a heating/cooling rate of $5 \mathrm{~K} \cdot \mathrm{min}^{-1}$ with a gas rate of $100 \mathrm{ml} \cdot$ $\min ^{-1}$. Oxygen partial pressure $p\left(\mathrm{O}_{2}\right)$ controlled by flowing pure $\mathrm{O}_{2}, \mathrm{~N}_{2}, \mathrm{CO}_{2}$ and a mixture gas of 1000 ppm $\mathrm{O}_{2}-\mathrm{N}_{2}$. The $p\left(\mathrm{O}_{2}\right)$ was monitored at the outlet of the TG-DTA chamber by a zirconia sensor. All the samples were preheated at $1273 \mathrm{~K}$ for 1 hour in $1000 \mathrm{ppm} \mathrm{O}_{2}-\mathrm{N}_{2}$. The usual sample for TG-DTA measurement was 98-100 mg. 


\subsection{High-temperature X-ray diffraction (HT-XRD)}

X-ray diffractometer (D8 Advance with LYNXEYETM Super Speed Detector, Bruker AXS, and $\mathrm{CuK} \alpha$ radiation) was used for in situ high-temperature powder X-ray diffraction (HT-XRD) measurements. The BSCF powder was set on a platinum heater inside the XRD chamber. In order to investigate the chemical stability in pure $\mathrm{O}_{2}$, the XRD patterns were measured in the $p\left(\mathrm{O}_{2}\right)$ range of $p\left(\mathrm{O}_{2}\right)=1 \times 10^{-4}$ to 1 bar using $\mathrm{O}_{2}-\mathrm{N}_{2}$ mixture gases. The XRD patterns were obtained at every $100 \mathrm{~K}$ with $20 \mathrm{~min}$ dwell time.

\section{Results and Discussion}

\subsection{Phase stability under high $p\left(\mathrm{O}_{2}\right)$}

Fig. 1 shows the TG and DTA curves of BSCF, BSCN and BSCFN during two heating and cooling thermal cycles in $1000 \mathrm{ppm} \mathrm{O}_{2}$. As seen in Fig.1, the weights of all samples decreased with increasing temperature from RT to $1273 \mathrm{~K}$ and then increased monotonously with cooling temperature back to RT. About $1 \%$ weight changes were observed for all three samples in the thermal cycles. Such a weight change is considered due to the oxygen vacancy formation and oxygen cooperation. These results indicated that all samples were stable in 1000ppm $\mathrm{O}_{2}-\mathrm{N}_{2}$ atmosphere.

Fig. 2 shows the TG and DTA curves of BSCF, BSCN and BSCFN in pure $\mathrm{O}_{2}$ gas. 
When the temperature was increased up to around $500 \mathrm{~K}$, a slight weight gain was observed for all three samples due to oxygen absorption of the relaxation process from the metastable quenched state to equilibrium state of sample. This was probably because of the oxygen nonstoichiometry compensation owing to the different $p\left(\mathrm{O}_{2}\right)$ employed in calcination, $p\left(\mathrm{O}_{2}\right)=10^{-3}$ bar , and TG-DTA measurements, $p\left(\mathrm{O}_{2}\right)=1$ bar. Around $500 \mathrm{~K}$, an obvious exothermic peak was observed in DTA curves of the BSCF. Simultaneously, an apparent weight increase was observed in the TG curve of BSCF from 500 to $680 \mathrm{~K}$. The exothermic peak and the weight change indicated decomposition of BSCF in high $p\left(\mathrm{O}_{2}\right)$. This agreed with HT-XRD results shown in Fig. 3, BSCF decomposed to mixture phases when temperature heating up to higher than $673 \mathrm{~K}$. This decomposition is probably driven by oxidizing of Co ionic in high $p\left(\mathrm{O}_{2}\right)$. Therefore, this decomposition absorbs more oxygen to cooperate with high oxidation state Co ionic. In Fig. 2 no obvious exothermic peaks were observed in the DTA curves of BSCN and BSCFN. These indicate the substitution of $\mathrm{Nb}$ into the B-site improved the stability of cubic perovskite phase of BSCF under high $p\left(\mathrm{O}_{2}\right)$. In our previous work [14], we found the oxidation of Co ions caused the decomposition of the cubic BSCF under high $p\left(\mathrm{O}_{2}\right)$. It is considered that the doping of high valence $\mathrm{Nb}$ into the $\mathrm{B}$-site lowered the Co mean valence and consequently improved the chemical stability of BSCF under high $p\left(\mathrm{O}_{2}\right)$. 


\subsection{Chemical stability against $\mathrm{CO}_{2}$ poisoning}

Fig. 4 shows the TG-DTA results of BSCF, BSCN and BSCFN samples during two heating and cooling cycles between 300 and $1273 \mathrm{~K}$ in $1000 \mathrm{ppm} \mathrm{O}_{2}-\mathrm{N}_{2}$ containing 5 vol $\% \mathrm{CO}_{2}$. A significant weight gain, approximately $4 \%$, was observed with BSCF at $750 \mathrm{~K}$ to $1125 \mathrm{~K}$. This weight gain was caused by formations of $\mathrm{Ba}$ and $\mathrm{Sr}$ carbonate. When temperature heated up to above $1123 \mathrm{~K}$, a significant weight loss and simultaneously exothermic peaks of BSCF were observed owing to the carbonate decomposition and formation of oxygen vacancies Vo “. The TG curves of BSCN and BSCFN in Fig. 4 showed obviously different weight change behaviors from that of BSCF. This indicated the $\mathrm{Nb}$ substitution in the B-site effectively suppressed the formation of carbonates in $5 \mathrm{vol} \% \mathrm{CO}_{2}$ containing atmosphere. However, although the chemical stability of $\mathrm{BSCF}$ against $\mathrm{CO}_{2}$ had greatly improved by $\mathrm{Nb}$ doping, a small amount of carbonate might be formed in BSCN and BSCFN in $\mathrm{CO}_{2}$-containing atmosphere, because the weight losses of BSCN and BSCFN were slightly smaller compared with those under the same $p\left(\mathrm{O}_{2}\right)$ condition without $\mathrm{CO}_{2}$, Fig.1.

Fig. 5 shows the TG-DTA results of BSCF, BSCN and BSCFN in $\mathrm{O}_{2}$ with 5 vol\% $\mathrm{CO}_{2}$. Small weight gains were observed with all three samples during heating up to 500 K. During further heating BSCF showed a large weight increase from 750 to $1120 \mathrm{~K}$. 
On the other hand BSCN and BSCFN showed a gradual weight decrease with increasing temperature up to $1273 \mathrm{~K}$ and then increased monotonously with cooling temperature back to RT. The TG-DTA results in Fig.5 demonstrated once again that the $\mathrm{Nb}$ substitution in the B-site effectively improved the chemical stability of BSCF-based materials against $\mathrm{CO}_{2}$. The weight change of $\mathrm{BSCF}$ due to the carbonate formation was relatively smaller in pure $\mathrm{O}_{2}$ than $1000 \mathrm{ppm} \mathrm{O}_{2}$. In other words, BSCF in pure $\mathrm{O}_{2}$ gas containing 5 vol\% $\mathrm{CO}_{2}$ atmospheres showed better stability than in $1000 \mathrm{ppm} \mathrm{O}_{2}$ gas containing 5 vol\% $\mathrm{CO}_{2}$ atmospheres. This suggested $p\left(\mathrm{O}_{2}\right)$ also affect carbonate formation. The primary cause is the relative high valence state of Co ions in high $p\left(\mathrm{O}_{2}\right)$ increased the acidity of BSCF and reduced carbonate formation.

Let us first discuss the $p\left(\mathrm{O}_{2}\right)$ effect on carbonate formation of pure BSCF. For decomposition of oxides containing trivalent $\mathrm{Co}$ ions in $\mathrm{CO}_{2}$, we should consider reduction of Co ions. For instance, the decomposition of alkaline earth cobaltite can be expresses by the following reaction:

$$
\mathrm{MCoO}_{3-\delta}+\mathrm{CO}_{2} \Leftrightarrow \mathrm{MCO}_{3}+\mathrm{CoO}+\frac{1-\delta}{2} \mathrm{O}_{2}
$$

where $\mathrm{M}$ is alkaline earth mental. Then the equilibrium constant of this reaction, $K_{c}$, can be written as:

$$
K_{\mathrm{c}} a_{\mathrm{MCoO}_{3-\delta}} p\left(\mathrm{CO}_{2}\right)=a_{\mathrm{MCO}_{3}} a_{\mathrm{CoO}}\left[p\left(\mathrm{O}_{2}\right)\right]^{(1-\delta) / 2}
$$


where $a_{\mathrm{MCOO}_{3-\delta}}, a_{\mathrm{MCO}_{3}}$ and $a_{\mathrm{CoO}}$ are the activities of $\mathrm{MCoO}_{3-\delta}, \mathrm{MCO}_{3}$ and $\mathrm{CoO}$, $p\left(\mathrm{CO}_{2}\right)$ and $p\left(\mathrm{O}_{2}\right)$ are the partial pressures of $\mathrm{CO}_{2}$ and $\mathrm{O}_{2}$, respectively. Eq. (2) tells us the stability of the alkaline earth carbonate is related to $p\left(\mathrm{CO}_{2}\right)$ and $p\left(\mathrm{O}_{2}\right)$. At a constant $p\left(\mathrm{CO}_{2}\right)$, more carbonate are formed in lower $p\left(\mathrm{O}_{2}\right)$ condition. This corresponds well with TG-DTA results in Figs. 4 and 5. The maximum weight gain due to the carbonate formation was from $4 \%$ in pure $\mathrm{O}_{2}$, while it was $1.8 \%$ in 1000ppm $\mathrm{O}_{2}-\mathrm{N}_{2}$.

As already mentioned, BSCF becomes more stable by doping $\mathrm{Nb}$ into B-site. The reactivity of a material with an acidic gas, such as $\mathrm{CO}_{2}$ can be related to its acidity, and higher acidity of the material leads to better resistance against $\mathrm{CO}_{2}$ [18]. The following order of the acidity of metal oxides has been reported: $\mathrm{Nb}^{5+}>\mathrm{Co}^{4+}>\mathrm{Co}^{3+}>\mathrm{Fe}^{3+}>\mathrm{Co}^{2+}>\mathrm{Fe}^{2+}[19]$. In our previous work, we found $\mathrm{Co}$ ion in BSCF show nearly trivalent in high $p\left(\mathrm{O}_{2}\right)$ conditions [14]. The high valence state of Co ions increased the acidity of BSCF and reduced carbonate formation. Therefore BSCF shown better $\mathrm{CO}_{2}$-resistans in high $p\left(\mathrm{O}_{2}\right)$. When the $\mathrm{Nb}$ ions substituted for the $\mathrm{B}$-site, the valence sate of Co ions is considered to decrease. However, as suggested by N.C. Jeong et al. [19], $\mathrm{Nb}^{5+}$ shows very high acidity and thus it was considered $\mathrm{Nb}$ doping could improve the chemical stability of BSCF against $\mathrm{CO}_{2}$. 


\section{Conclusions}

In this study, the influence of the Nb-doping on the chemical stability of BSCF, BSCN and BSCFN under high $p\left(\mathrm{O}_{2}\right)$ and $\mathrm{CO}_{2}$-containing atmospheres were examined. An obvious exothermic peak on DTA and an apparent weight increase in TG from 500 to $680 \mathrm{~K}$ during heating in pure $\mathrm{O}_{2}$ proved the instability of BSCF in high $p\left(\mathrm{O}_{2}\right)$ condition. On the other hand, neither DTA peaks nor weight gains were observed in the TG-DTA of BSCN and BSCFN. These results indicated the doping of $\mathrm{Nb}$ for the B-site improved the chemical stability of BSCF under high $p\left(\mathrm{O}_{2}\right)$ condition. TG-DTA results in $\mathrm{CO}_{2}$-containing atmosphere demonstrated the $\mathrm{Nb}$-doping improved the $\mathrm{CO}_{2}$-tolerance of BSCF-based solid solution. In conclusion, the Nb-doped BSCF exhibited relatively high chemical stability under high $p\left(\mathrm{O}_{2}\right)$ as well as $\mathrm{CO}_{2}$ containing atmospheres.

\section{Acknowledgements}

This work was supported by CREST from the Japan Science and Technology Agency (JST) and Grant-in-Aid for Scientific Research of MEXT, Japan.

\section{References}

[1] Z.P. Shao, S.M. Haile, Nature 431 (2004) 170-173 
[2] F. S. Baumann, J. Fleig, H. -U. Habermeier, J. Maier, Solid State Ionics, 177(2006)1071-1081

[3] Y. Mastrikov, M.M. Kuklja, E.A. Kotomin, J. Maier, En. Env. Sci. 3 (2010) $1544-1550$

[4] S. Švarcová, K.Wiik, J. Tolchard, H.J.M. Bouwmeester, T. Grande, Solid State Ionics, 178 (2008) 1787-1791.

[5] M. Arnold, T.M. Gesing, J. Martynczuk, A. Feldhoff, Chem. Mater. 20 (2008) $5851-5858$

[6] D.N. Mueller, R.A. De Souza, T.E. Weirich, D. Roehrens, J. Mayer, M. Martin, Phys. Chem. Chem. Phys. 12 (2010) 10320-10328

[7] K. Efimov, Q. Xu, A. Feldhoff, Chem. Mater. 22 (2010) 5866-5875

[8] P. Müller, H. Störmer, L. Dieterle, C. Niedrig, E. Ivers-Tiffée and D. Gerthsen, Solid State Ionics, 206(2012) 57-66.

[9] M. M. Kuklja, E. A. Kotomin, R. Merkle, Yu. A. Mastrikov and J. Maier, Phys. Chem. Chem. Phys., 15 (2013) 5443-5471.

[10] M. Arnold, H.H. Wang, A. Feldhoff, J. Membr. Sci. 293 (2007) 44-52

[11] A.Y. Yan, L. Bin, Y.L. Dong, Z.J. Tian, D.Z. Wang, M.J. Cheng, Appl. Catal. B 80 (2008) 24-31 
[12] W. Zhou, R. Ran, Z.P. Shao, J. Power Sources 192 (2009) 231-246

[13] S. McIntosh, J.F. Vente, W. G. Haije, D. H.A. Blank, H. J.M. Bouwmeester, Solid State Ionics 177 (2006) 1737-1742

[14] F. Wang, K. Yashiro, K. Amezawa, J. Mizusaki, 13th Asian Conference on Solid State Ionics, Sendai, Miyagi, Japan, 2012

[15] T. Nagai, W. Ito, T. Sakon, Solid State Ionics 177 (2007) 3433-3444

[16] W. Ito, T. Nagai, T. Sakon, Solid State Ionics 178 (2007) 809-816

[17] S.M. Fang, C.Y. Yoo, H.J.M. Bouwmeester, Solid State Ionics, 195, 1 (2011)

[18] J.X. Yi, M. Schroeder, T. Weirich, J. Mayer, Chem. Mater. 22(2010) 6246

[19] N. C. Jeong, J. S. Lee, E. L. Tae, Y. J. Lee, K. B. Yoon, Angew. Chem., Int. Ed. $47(2008) 10128$

\section{Figure Captions}

Fig. 1: TG and DTA curves of BSCF (solid line), BSCN (dash line) and BSCFN (dot line) of two heating-cooling thermal cycles in $1000 \mathrm{ppmO}_{2}-\mathrm{N}_{2}$.

Fig. 2: TG and DTA curves of BSCF (solid line), BSCN (dash line) and BSCFN (dot line) of two heating-cooling thermal cycles in $100 \% \mathrm{O}_{2}$.

Fig. 3 Powder XRD patterns of $\mathrm{Ba}_{0.5} \mathrm{Sr}_{0.5} \mathrm{Co}_{0.8} \mathrm{Fe}_{0.2} \mathrm{O}_{3-\delta}$ during heating in $p\left(\mathrm{O}_{2}\right)=1$ bar. Closed Inverted triangle indicates the impurity phase. 
Fig. 4: TG and DTA curves of BSCF (solid line), BSCN (dash line) and BSCFN (dot line) of two heating-cooling thermal cycles in 1000ppm $\mathrm{O}_{2}-\mathrm{N}_{2}$ containing $5 \mathrm{vol} \% \mathrm{CO}_{2}$.

Fig. 5: TG and DTA curves of BSCF (solid line), BSCN (dash line) and BSCFN (dot line) of two heating-cooling thermal cycles in $5 \mathrm{vol} \% \mathrm{CO}_{2}-95 \mathrm{vol} \% \mathrm{O}_{2}$. 
Fig. 1

Gas: 1000ppmO $-\mathrm{N}_{2}$

(Heating/cooling rate is $5 \mathrm{~K} / \mathrm{min}$ )

Heating $1273 \mathrm{~K}$ Cooling Heating $1273 \mathrm{~K}$ Cooling

$300 \mathrm{~K}$ to $1273 \mathrm{~K}$ ih $1273 \mathrm{~K}$ to $300 \mathrm{~K} 300 \mathrm{~K}$ to $1273 \mathrm{~K}$ ih $1273 \mathrm{~K}$ to $300 \mathrm{~K}$

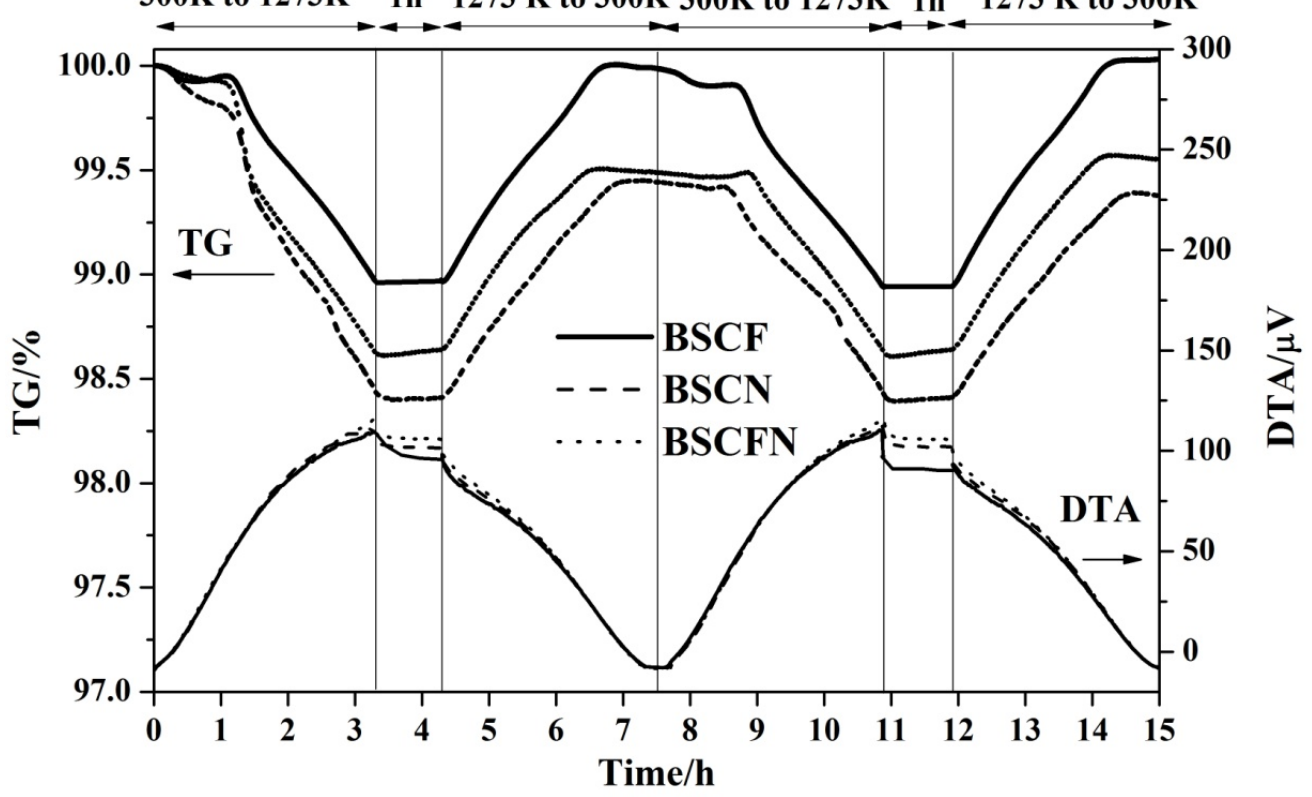

Fig. 2

Gas: $100 \% \mathrm{O}_{2}$

(Heating/cooling rate is $5 \mathrm{~K} / \mathrm{min}$ ) Heating $1273 \mathrm{~K}$ Cooling Heating $1273 \mathrm{~K}$ Cooling $300 \mathrm{~K}$ to $1273 \mathrm{~K} 1 \mathrm{~h} 1273 \mathrm{~K}$ to $300 \mathrm{~K} 300 \mathrm{~K}$ to $1273 \mathrm{~K} 1 \mathrm{~h} 1273 \mathrm{~K}$ to $300 \mathrm{~K}$

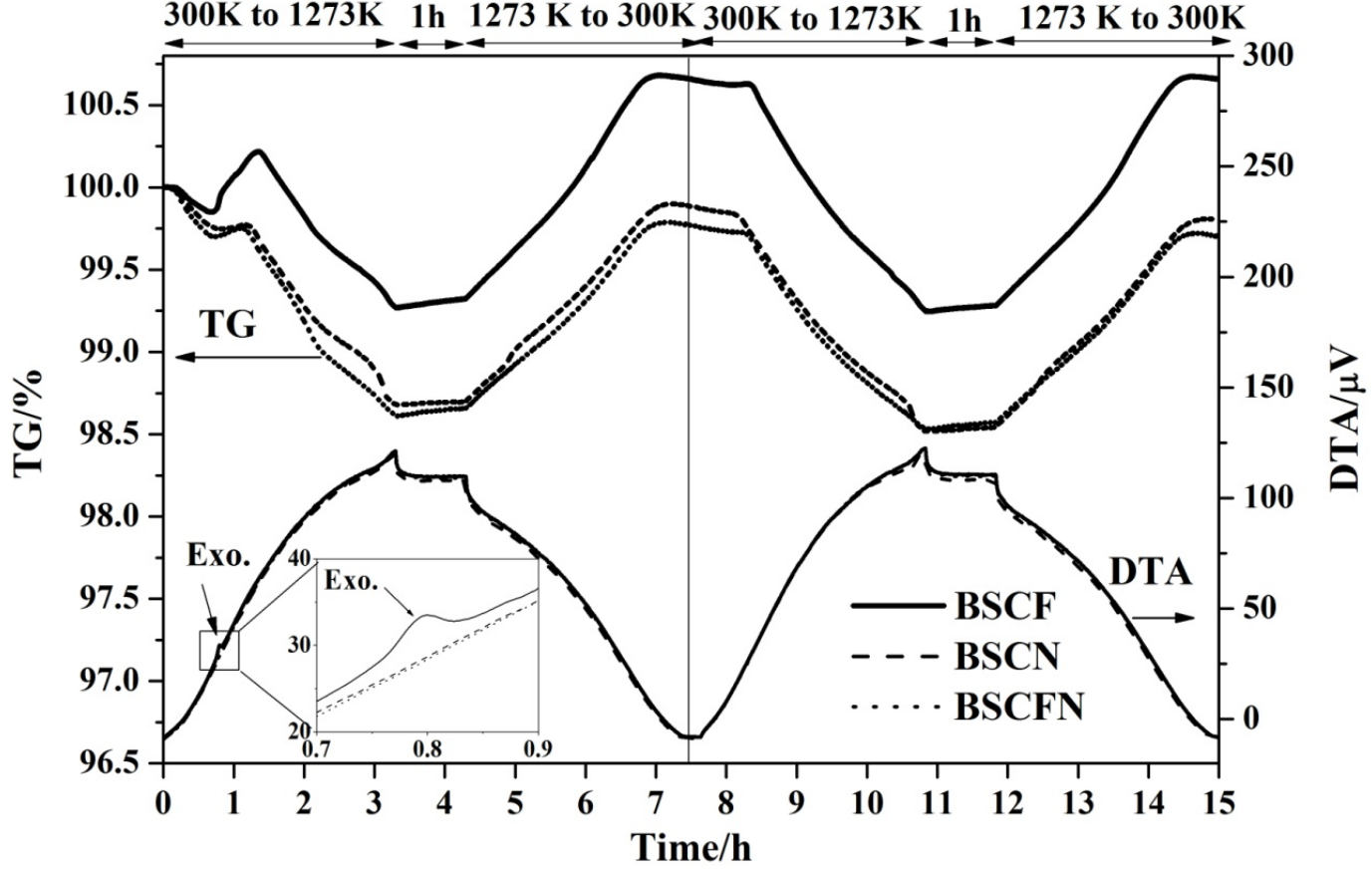


Fig. 3

BSCF heating in $p\left(\mathrm{O}_{2}\right)=1$ bar

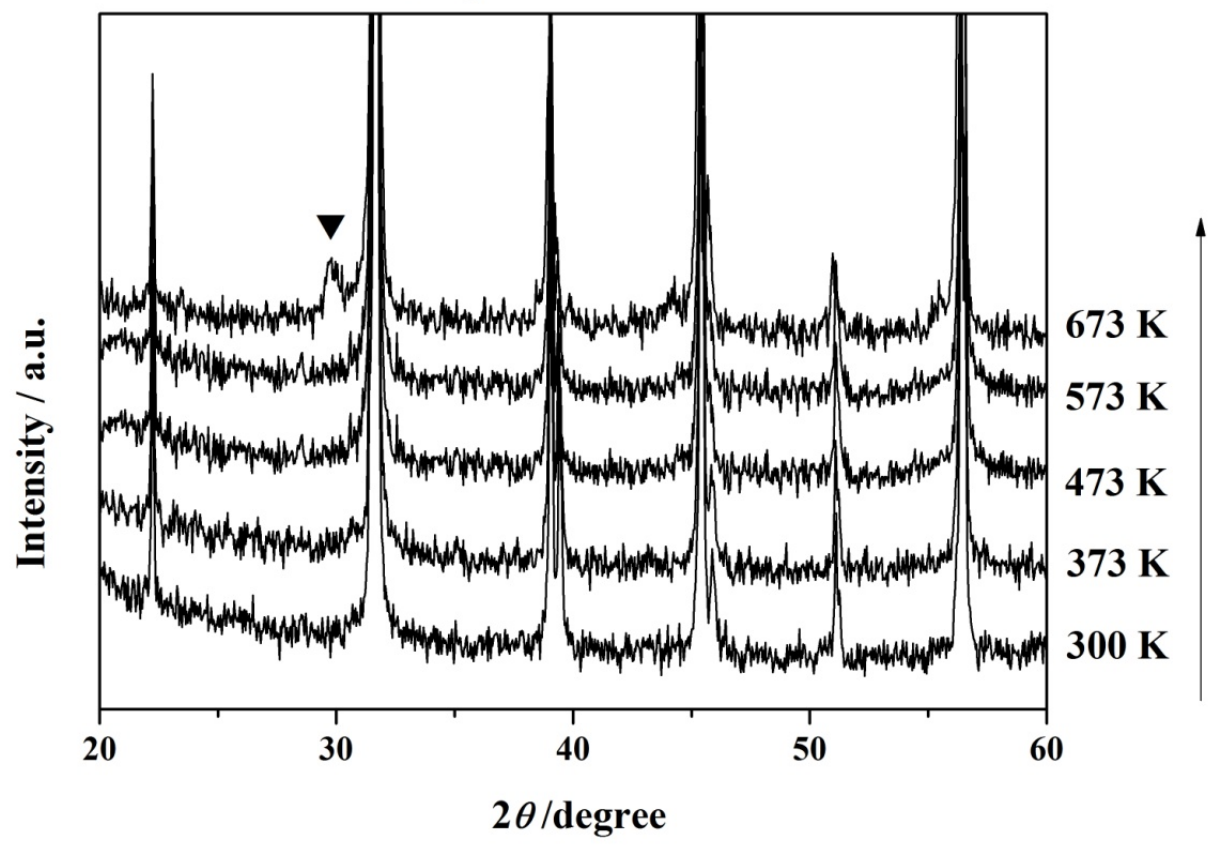

Fig. 4

Gas: 1000ppm $\mathrm{O}_{2}-\mathrm{N}_{2}$-containing 5\% $\mathrm{CO}_{2}$ (Heating/cooling rate is $5 \mathrm{~K} / \mathrm{min}$ ) Heating $1273 \mathrm{~K}$ Cooling Heating $1273 \mathrm{~K}$ Cooling $300 \mathrm{~K}$ to $1273 \mathrm{~K} \quad 1 \mathrm{~h} 1273 \mathrm{~K}$ to $300 \mathrm{~K} 300 \mathrm{~K}$ to $1273 \mathrm{~K} 1 \mathrm{~h} 1273 \mathrm{~K}$ to $300 \mathrm{~K}$

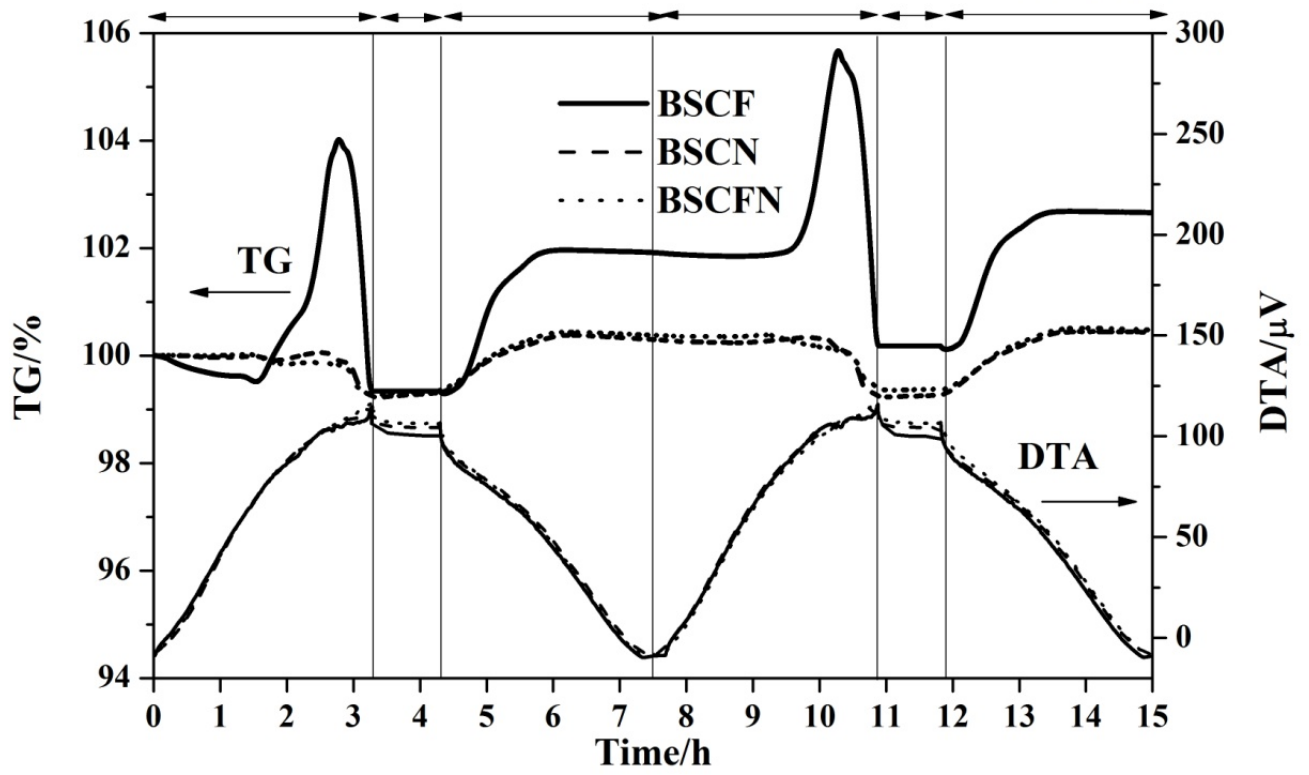


Fig. 5

Gas: $5 \% \mathrm{CO}_{2}-95 \% \mathrm{O}_{2} \quad$ (Heating/cooling rate is $5 \mathrm{~K} / \mathrm{min}$ )

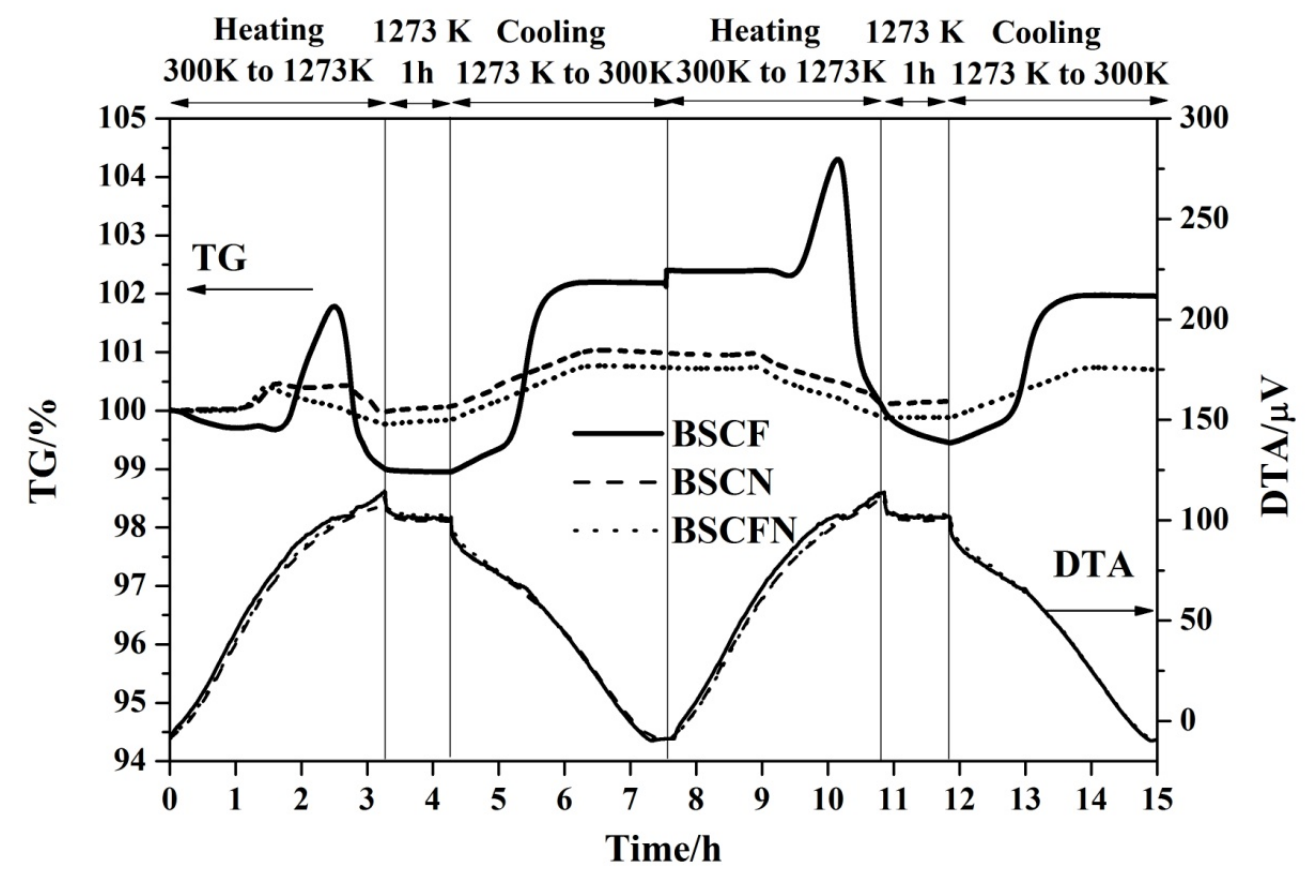

